\title{
Thermo-/pH-dual responsive properties of hyperbranched polyethylenimine grafted by phenylalanine
}

\author{
Jie Chen $\cdot$ Jialiang Xia $\cdot$ Huayu Tian . \\ Zhaohui Tang $\cdot$ Chaoliang He $\cdot$ Xuesi Chen
}

Received: 30 August 2013/ Accepted: 31 October 2013/Published online: 22 November 2013

(c) The Author(s) 2013. This article is published with open access at Springerlink.com

\begin{abstract}
Novel thermo- and $\mathrm{pH}$-dual responsive amphiphilic copolymers were synthesized based on hyperbranched polyethylenimine (PEI) by grafting L-phenylalanine. The phenylalanine-modified PEI exhibited lower cytotoxicity than commercial PEI. These copolymers showed the phenomena of phase transitions in response to $\mathrm{pH}$ and temperature. The dilute copolymer solution at lower $\mathrm{pH}$ displayed the higher LCST. Furthermore, LCST increased with the increasing of phenylalanine grafting density. LCST of these copolymers were tunable from 7.2 to $59.6{ }^{\circ} \mathrm{C}$ by the degree of amidation and $\mathrm{pH}$ of solution. DLS and TEM experiments certified that the copolymer chains aggregated to form small size particles as increasing the temperature above LCST. For these reasons, the obtained smart copolymers were considered to be potential gene/drug carriers in biomedical field.
\end{abstract}

Keywords Amphiphilic polymers - Thermal- and pH-dual responsive Phenylalanine .

Polyethylenimine

\section{Introduction}

Polymers with stimuli-responsive property, such as fast and reversible changes in response to variations in temperature,

J. Chen $\cdot$ H. Tian $(\bowtie) \cdot$ Z. Tang $\cdot$ C. He $\cdot$ X. Chen

Key Laboratory of Polymer Ecomaterials, Changchun Institute

of Applied Chemistry, Chinese Academy of Sciences,

Changchun 130022, China

e-mail: thy@ciac.ac.cn

J. Xia

College of Chemistry Science and Technology, Zhanjiang

Normal University, Zhanjiang 524048, China
$\mathrm{pH}$, redox, light or electric fields, have attracted much interest in the past decade due to their medical and biological applications (Dobrynin and Rubinstein 2005; Kim and Oh 2005; Costa et al. 2009; Won et al. 2011; Liu et al. 2012; Yu et al. 2012). In particular, thermo- and $\mathrm{pH}-$ responsive polymers have been particularly attractive and intensively investigated for biomedical applications, including drug/gene delivery systems, injectable tissue engineering scaffolds, biosensors etc (Chaterji et al. 2007; Oda et al. 2010; Strozyk et al. 2012). It has been well known that some tissues and cellular compartments have different $\mathrm{pH}$ environments compared with normal physiological $\mathrm{pH}$. Mean while, the temperature of specific sites in the body can be changed safely by hyperthermia, such as tumor tissues (Kojima et al. 2009; Alarcon et al. 2005; Schmaljohann 2006).

Thermo- and $\mathrm{pH}$-responsive polymers exhibit the particularly attractive potential for biomedical applications because of the undergoing of a transition between watersoluble and water-insoluble states (Pang et al. 2011; Amin et al. 2012; Cha et al. 2012; Chen et al. 2013a). Among them, amphiphilic block copolymers containing amide segments have their natural property in thermo-sensitivity and the thermo-sensitivity can be adjusted by the number of amide bond, the ratios of hydrophilic and hydrophobic groups, and the length of hydrophilic and hydrophobic groups. Different response temperatures of the sensitive polymers have been synthesized by introducing a large number of amide bonds to hyperbranched poly(glycido). The LCSTs of polymers decrease with enhancing the hydrophobicity around the amide bond (Sakaguchi et al. 2008; Kojima et al. 2009). Typically, amino groups were utilized as $\mathrm{pH}$-sensitive elements because of their ability of protonation/deprotonation. Liu and coworkers transformed all the end groups of hyperbranched PEI (HPEI) with 
propionyl chloride into isobutyramide groups, and obtained sensitive polymers both with thermo- and $\mathrm{pH}$-sensitivity (Liu et al. 2007). However, the transition curves of light transmittance versus temperature were less sharp. Presumably, the entire primary amino of PEI was absolutely reacted, and the ability of protonation was limited due to the small amount of scanty tertiary amino groups. Using NHS/EDC $\cdot \mathrm{HCl}$ condensation reaction, different hydrophobic amino acids were grafted onto poly(amidoamine) dendrimers, and the target polymers were provided with the ability of owing different range of thermo- and $\mathrm{pH}$-sensitive (Haba et al. 2004, 2006; Tono et al. 2006).

Phenylalanine (Phenylalanine, abbreviated as Phe) is a natural amino acid with a hydrophobic phenyl group. Its carboxyl group can react with an amino group of another polymer and produce a temperature-sensitive amide bond. The amino group can provide $\mathrm{pH}$ sensitivity, and the phenyl group can provide hydrophobicity. Therefore, phenylalanine is a novel candidate to prepare thermo- and pH-dual sensitive polymers. However, very little attention has been paid to the application of phenylalanine in this regard (Tono et al. 2006; Casolaro et al. 2005). HPEI has exhibited many excellent performances due to the abundant levels of amino and their spatial structure (Park et al. 2008; Chen et al. 2009; Kim and Kim 2009; Tian et al. 2012). In 1995, PEI was successfully used for gene delivery (Boussif et al. 1995). Since then, a variety of structures based on PEI have been synthesized as candidates for the most efficient gene transfection reagents (Tian et al. 2007, 2013; Chen et al. 2013b). PEI can be easily prepared into biocompatible hydrogel (Lei et al. 2010). PEI can also absorb negatively charged materials in water due to its large number of positive charges. PEI can also be used in water treatment, paper industry, textile industry, oil drilling, and secondary recovery (Vicennati et al. 2008; Khaydarov et al. 2010).

In the present study, we synthesized a series of phenylalanine grafted PEI (abbreviated as PPhen, P means PEI, Phe means phenylalanine, and $\mathrm{n}$ means the molar feed ratio of phenylalanine to PEI) with thermo- and $\mathrm{pH}$-dual sensitive properties. Subsequently, the cell viability of PPhen copolymers was evaluated compared with the commercial PEI. Furthermore, the factors that response to temperature and $\mathrm{pH}$ were investigated by controlling the relative proportions of amide segments.

\section{Materials and methods}

Materials

HPEI with a number average molecular weight of $10 \mathrm{kDa}$ and weight-average molecular weight of $25 \mathrm{kDa}$ (PEI25 K) was purchased from Aldrich. Boc-L-phenylalanine (Boc-Phe-OH) was purchased from Sigma and used as received. $\mathrm{N}$ Hydroxysuccinimide (NHS) was purchased from Aesar Alfar (Ward Hill, MA, USA). Dimethylformamide (DMF) was treated with $\mathrm{CaH}_{2}$ and distilled before use. All other chemicals were purchased from Sigma-Aldrich (Munich, Germany). 3-(4,5-Dimethylthiazol-2-yl)-2,5-diphenyltetrazolium bromide (MTT) was purchased from Amresco (Solon, OH, USA). Dulbecco's modified Eagle's medium (DMEM) and fetal bovine serum (FBS) were purchased from Gibco (Grand Island, USA).

\section{Synthesis of PPhen copolymers}

A series of hyperbranched and amphiphilic PPhen copolymers were synthesized as shown in Fig. 1. Briefly, PEI25 K (2.0 g, $0.2 \mathrm{mmol})$, Boc-Phe-OH $(0.2 n \mathrm{mmol}, n$ is the molar ratio of Boc-Phe-OH to PEI25 K), and NHS $(0.4 n \mathrm{mmol})$ were dissolved in dried DMF $(30 \mathrm{~mL})$. DCC $(0.4 n \mathrm{mmol})$ was added under the condition of ice bash after the powder was completely dissolved. The solution was stirred for $2 \mathrm{~h}$ at $0{ }^{\circ} \mathrm{C}$, and then the temperature was increased to $25^{\circ} \mathrm{C}$ for another $48 \mathrm{~h}$. The solutions were precipitated twice with excess ethylether under vigorous stirring. Each PEI-(Phe-Boc)n copolymer was obtained after being dried under vacuum at room temperature.

The Butyloxycarbonyl groups in the PEI-(Phe-Boc)n were removed to obtain PPhen by TFA. Briefly, take the preparing of PPhe 40 for instance, PEI-(Phe-Boc)40 (1.0 g) was dissolved in $5 \mathrm{~mL}$ of DMF at room temperature. Then $2 \mathrm{~mL}$ of TFA was added and stirred for $2 \mathrm{~h}$. The solution was added dropwise into an excess of ethylether. The product was collected and dried under vacuum at room temperature overnight. The solid was dissolved in DMF and dialyzed (3,500 molecular weight cut off) against water. The final product (PPhe40) was collected by lyophilization.

Proton nuclear magnetic resonance $\left({ }^{1} \mathrm{H}\right.$ NMR) spectra were recorded in deuteroxide at room temperature by using a Bruker AV-400 NMR spectrometer (Bruker, Germany). Fourier-transform infrared (FT-IR) spectra of the PPhen copolymers were measured on a Vertex 70 FT-IR spectrometer (Bruker, Germany) using the $\mathrm{KBr}$ disk method.

\section{Cytotoxicity assay}

Human epithelial carcinoma cells (HeLa cells) were cultured in DMEM medium, which was supplemented with $10 \%(\mathrm{v} / \mathrm{v})$ heat-inactivated FBS, $100 \mathrm{U} / \mathrm{mL}$ penicillin, and $100 \mu \mathrm{g} / \mathrm{mL}$ streptomycin in a $5 \% \mathrm{CO}_{2}$ incubator at $37{ }^{\circ} \mathrm{C}$ under $95 \%$ humidity. HeLa cells were seeded in 96-well plates at a density of $1 \times 10^{4}$ cells/well and incubated for $24 \mathrm{~h}$ prior to the treatment of polymer solutions with the concentration range from 0.015 to $1.0 \mathrm{mg} / \mathrm{mL}$. After another $24 \mathrm{~h}, 20 \mu \mathrm{L}$ of 
<smiles>CCOCCP</smiles><smiles>CC(C)(C)OC(=O)NC(Cc1ccccc1)C(=O)O</smiles>

Boc-Phe-OH

\section{NHS / DCC}

2. TFA<smiles>[R]NCCN(C)CCN(C)CCC(C)(C)N[R7]</smiles>

PPhen<smiles></smiles>

Fig. 1 Synthesis of hyperbranched copolymers (PPhen)

MTT solution ( $5 \mathrm{mg} / \mathrm{mL}$ in PBS) was added to each well. The MTT solution was carefully removed from each well after $4 \mathrm{~h}$, and then $150 \mu \mathrm{L}$ of DMSO was added to dissolve the MTT formazan crystals. The cell viability was analyzed by an ELISA microplate reader (Bio-Tek Instruments Inc., USA) according to the manufacturer's protocol. The cell viability (\%) was calculated according to the following equation:

Cell viability $(\%)=\left(\mathrm{A}_{\text {sample }} / \mathrm{A}_{\text {control }}\right) \times 100$

where $\mathrm{A}_{\text {sample }}$ was the absorbance of the polymers treated cells and $\mathrm{A}_{\text {control }}$ was the absorbance of the untreated cells. Each experiment was performed as the average values of six runs and repeated a minimum of three times.

Transmission electron microscopy (TEM) imaging of PPhen copolymers

TEM images were obtained using a TEM instrument (JEM2010HR, Japan) in a $100 \mathrm{kV}$. To prepare the TEM samples, $0.1 \mu \mathrm{g} / \mu \mathrm{L}$ of the samples solution were pre-equilibrated at 25 and $40{ }^{\circ} \mathrm{C}$. One drop of each sample was dropped onto a 300 mesh carbon-coated copper grid and dried at 25 and $40{ }^{\circ} \mathrm{C}$, respectively.

\section{Measurement of phase transition}

Phase transition measurements were carried out on a UV/ vis spectrometer (Shimadzu UV-2401PC) equipped with a temperature controller (Shimadzu S-1700). Briefly, the turbidity of solutions of PPhen was measured at $500 \mathrm{~nm}$ in $50 \mathrm{mM}$ phosphate containing $150 \mathrm{mM} \mathrm{NaCl}$ buffer, $\mathrm{pH}$ 6.8-12.2. The heating rate of the sample cell was maintained at $2{ }^{\circ} \mathrm{C} / \mathrm{min}$ over the temperature range of $5-75{ }^{\circ} \mathrm{C}$. The concentration of the polymers was $2 \mathrm{mg} / \mathrm{mL}$. The LCST was defined as the temperature corresponding to the initial break points in the resulting transmittance versus temperature curves. (Liu et al. 2007; Zhang et al. 2011)

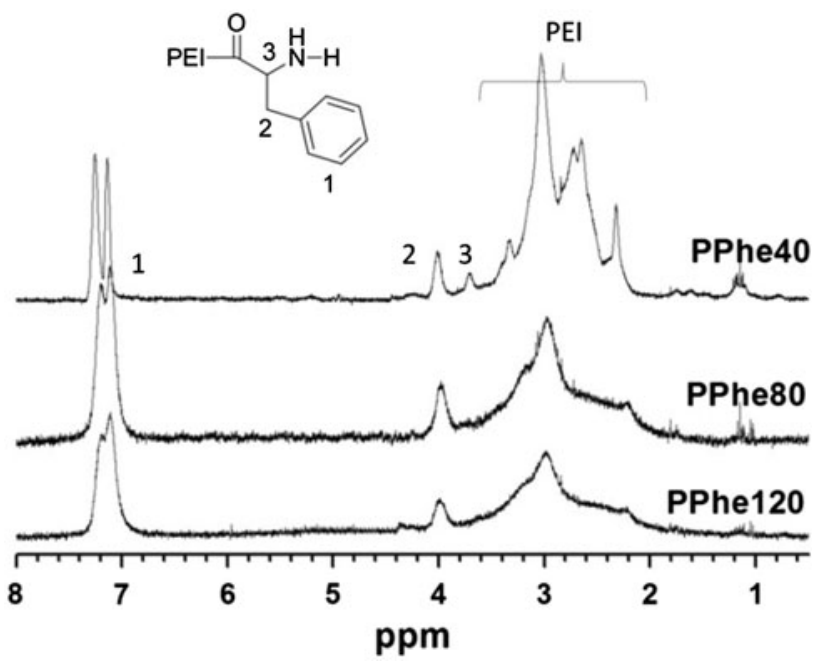

Fig. $2{ }^{1} \mathrm{H}$ NMR spectra of the PPhen copolymers in $\mathrm{D}_{2} \mathrm{O}$

\section{Results and discussion}

Synthesis and characterization of the PPhen copolymers

The synthetic route for the preparation of PPhen copolymer was outlined in Fig. 1. The feed molar ratios of Boc-Phe$\mathrm{OH}$ to PEI25 K were 40, 80, and 120, respectively. All the PPhen copolymers were well water soluble. The ${ }^{1} \mathrm{H}$ NMR spectra of the PPhen copolymers are presented in Fig. 2. The number of grafted Phe segments in the copolymers ( $\left.\mathrm{n}_{(\text {Phe in PPhe) }}\right)$ was estimated by ${ }^{1} \mathrm{H}$ NMR spectroscopy (Table 1), and $\mathrm{n}_{\text {(Phe in PPhe) }}$ was calculated according to the following formula:

$\mathrm{n}_{(\text {Phe in PPhen })}=\frac{10000}{43} \times \frac{4 \times \boldsymbol{I}_{\delta=7.18}}{5 \times \boldsymbol{I}_{\delta=2.3 \sim 3.4}}$

The FT-IR spectra of PEI25 K and PPhen copolymers are shown in Fig. 3. In the spectra, the absorption peak of 
Table 1 Characterization of PPhen copolymers

\begin{tabular}{llllll}
\hline Sample & \multicolumn{2}{l}{ Molar ratio of Phe/PEI } & & \multicolumn{2}{l}{ Phe content in PPhen (\%) } \\
\cline { 2 - 3 } \cline { 5 - 6 } & Theoretical $^{\mathrm{a}}$ & Calculative & & Theoretical $^{\mathrm{a}}$ & Calculative \\
\hline PPhe120 & $120: 1$ & $88: 1$ & & 63.8 & 56.4 \\
PPhe80 & $80: 1$ & $77: 1$ & & 54.0 & 53.1 \\
PPhe40 & $40: 1$ & $38: 1$ & & 37.0 & 35.8 \\
\hline
\end{tabular}

a The theoretical value was calculated based on PEI25 $\mathrm{K}$ with a number average molecular weight of $10 \mathrm{kDa}$

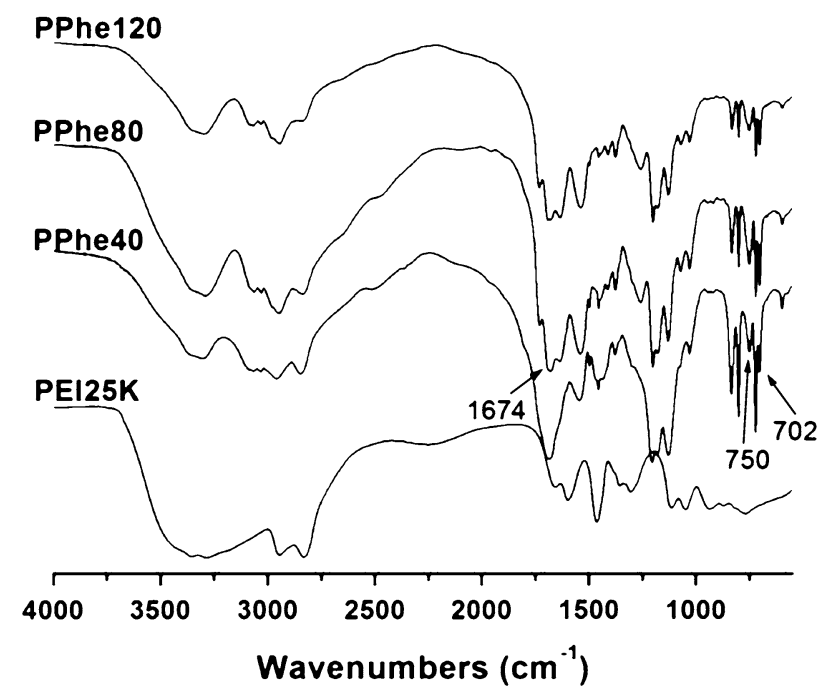

Fig. 3 The FT-IR spectra of PEI25 K and PPhen copolymers

amide groups at $1,674 \mathrm{~cm}^{-1}(\mathrm{HN}-\mathrm{C}=\mathrm{O})$ and the peaks at 702 and $750 \mathrm{~cm}^{-1}$ of monosubstituted benzene in the fingerprint indicated that the thermo- and $\mathrm{pH}$-sensitive copolymers were successfully prepared.

HPEI contains primary, secondary, and tertiary amines, and the molar ratios of them for PEI25 K were 31:39:30 according to their respective inverted gate ${ }^{13} \mathrm{C}$ NMR spectra. (Liu et al. 2007) In other words, a PEI25 K molecule contains the numbers of primary, secondary, and tertiary amines were 72,90 , and 70 , respectively. Primary amines of HPEI are much more reactive than the secondary amines. When the feed molar ratios of Boc-Phe-OH to PEI25 K were 40 and 80 , about 56 and $89 \%$ of the primary amines in HPEI were reacted to form amide bands, respectively. When the feed molar ratio was increased to 120 , all the primary amines were reacted completely and some secondary amines also participated in the reaction.

\section{Cytotoxicity of PPhen copolymers}

The cytotoxicity of PEI depends on the density of positive charges on its surface. The PPhen copolymers exhibited relatively low cytotoxicity for potential medical

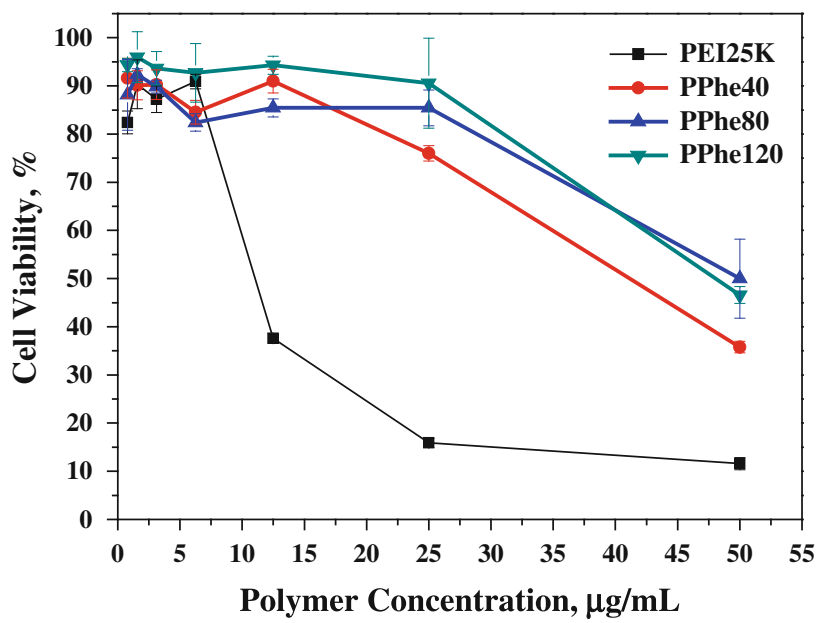

Fig. 4 Viability of HeLa cells exposed to various polymer concentrations for PEI $25 \mathrm{~K}$ and PPhen

applications, as compared with PEI25 K (Fig. 4). The improved cytocompatibility of PPhen copolymers may be due to the introduction of biocompatible and hydrophobic Phe moieties, which shield the high positive charge density on the surface of PEI.

Thermo- and $\mathrm{pH}$-responsive properties of PPhen copolymers

The phase transition behaviors of the copolymers were characterized by turbidimetry measurement on a UV/Vis spectrometer with temperature-controlled source at $500 \mathrm{~nm}$. The LCST was defined as the temperature corresponding to $90 \%$ transmittance of aqueous solution during the heating process. Figure 5 showed at different $\mathrm{pH}$ condition, the transmittance change of PPhe 80 and PPhe120 in aqueous solutions with a constant heating rate of $2{ }^{\circ} \mathrm{C} \mathrm{min}^{-1}$. As shown, the transmittance decreased dramatically in response to the temperature change around the LCST, indicating the highly sensitive phase separation of PPhe 80 and PPhe 120 copolymers.

With introducing of amide bond, the temperature-sensitive property could be bestowed to PEI25 K. Hydrogen bonds, formed by amide bonds, amino groups and $\mathrm{H}_{2} \mathrm{O}$ could provide good hydrophilicity of copolymers, and the hydrophilicity would be weakened by temperature rising. The phenyl groups of Phe could provide fixed hydrophobic interaction. Furthermore, the lower $\mathrm{pH}$ there was, the more amino groups protonated, which provide very strong hydrophilic property. Thus, PPhe 80 copolymer had a dual responsive property with the change of temperature and pH. As Fig. 5 and Table 2 showed, PPhe 80 showed the lower $\mathrm{pH}$, the higher LCST. PPhe 80 exhibited rapid temperature response between the $\mathrm{pH}$ values of 8.0-12.2. And with the $\mathrm{pH}$ value increased, LCST reduced from 47.4 to 


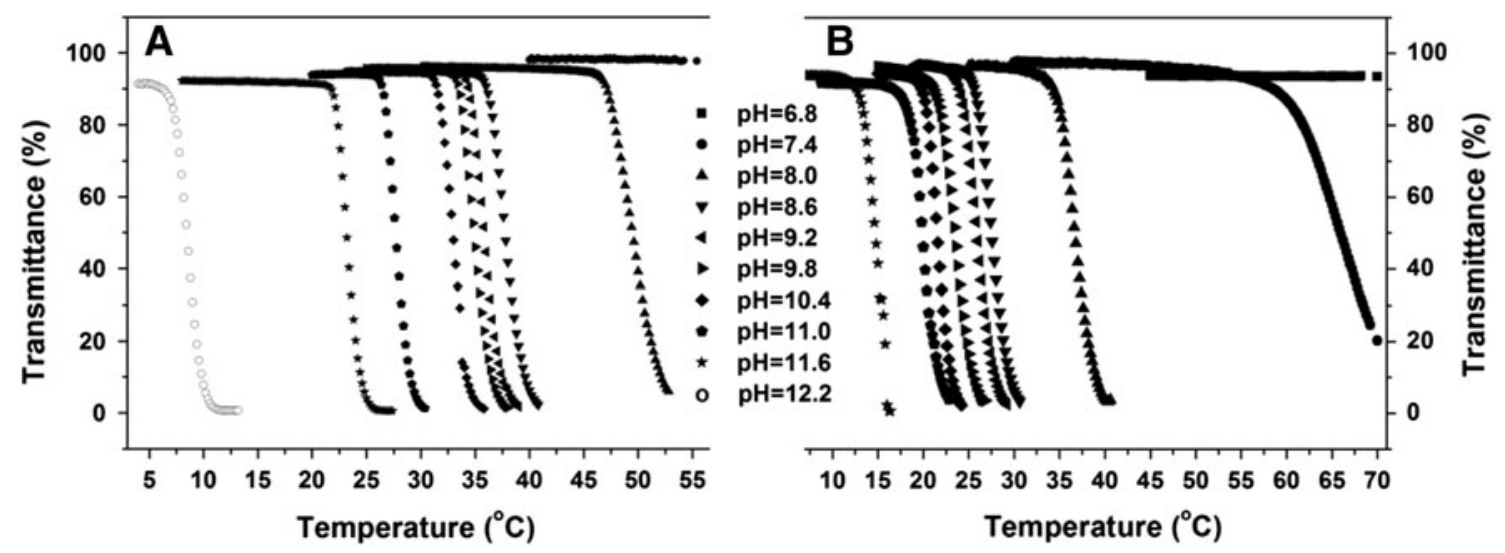

Fig. 5 Effect of temperature on the phase transition behavior of PPhe80 (a) and PPhe120 (b) at different pH values

Table 2 The $\operatorname{LCST}\left({ }^{\circ} \mathrm{C}\right)$ of PPhen copolymers at different $\mathrm{pH}$ values

\begin{tabular}{lcccccccccc}
\hline Polymers & $\mathrm{pH}$ & \multicolumn{10}{c}{} & & & & & \\
\cline { 2 - 9 } & 6.8 & 7.4 & 8.0 & 8.6 & 9.2 & 9.8 & 10.4 & 11.0 & 11.6 & 12.2 \\
\hline PPhe120 & - & 59.6 & 34.8 & 25.8 & 24.2 & 21.8 & 20.2 & 18.8 & 13.2 & - \\
PPhe80 & - & - & 47.4 & 36.4 & 34.6 & 33.8 & 31.8 & 26.8 & 22.2 & 7.2 \\
PPhe40 & - & - & - & - & - & - & - & - & - \\
\hline
\end{tabular}

(-) indicates that LCSTs could not be detected at their corresponding $\mathrm{pH}$ values, in the tested temperature range

$7.2{ }^{\circ} \mathrm{C}$. When the $\mathrm{pH}$ value exceeded 11 , PPhe80 copolymer was not soluble in water at room temperature.

The influence of the relative proportions of Phe groups and PEI25 K were also investigated. Different phenylalanine grafting density of PPhe40, PPhe80 and PPhe120 were prepared by adjusting the feed ratio of Boc-Phe-OH and PEI25 K. The LCSTs of PPhe40, PPhe80 and PPhe120 at different $\mathrm{pH}$ values were summarized in Table 2. Figure $5 \mathrm{~b}$ showed that, with similar properties of PPhe80, the PPhe120 solution exhibited rapid temperature response. LCST of the PPhe120 solution reduced from 59.6 to $13.2{ }^{\circ} \mathrm{C}$ with $\mathrm{pH}$ values increased from 7.4 to 11.6 . Compared the results of Table 2, LCST of PPhe120 was lower than that of PPhe 80 at the same $\mathrm{pH}$ value. PPhe120 has more benzene rings and amide bonds than PPhe80, so that the lower temperature could make the hydrophobic effect played a dominant role. For PPhe40 copolymer, there was only a few of benzene rings and amide bonds, the protonation ability and hydration were overwhelmingly dominant, so it did not exist LCST transition.

Figure $6 a-c$ showed the size distributions of PPhen copolymers at $0.5 \mathrm{mg} / \mathrm{mL}$ with increasing temperature at different pHs by DLS assay. LCST of PPhe80 was $33.8^{\circ} \mathrm{C}$ at $\mathrm{pH} 9.8$. When the temperature was $25^{\circ} \mathrm{C}$, the average particle size of PPhe80 was $246 \mathrm{~nm}$. (Fig. 6b) Under this condition, the PPhe 80 copolymer was in a relatively loose aggregation state because of the dominant position of hydrophilic interaction. However, when the temperature was $40{ }^{\circ} \mathrm{C}$, the average particle size of PPhe80 was $88.5 \mathrm{~nm}$. The hydrophobic interaction was in a good condition at this time. The aggregation state of PPhe80 was further compressed in the hydrophobic effect caused by benzene rings and amide bonds. LCST of PPhe120 was $34.8{ }^{\circ} \mathrm{C}$ at $\mathrm{pH} 8.0$. Figure $6 \mathrm{c}$ showed that the average particle size of PPhe120 was $201 \mathrm{~nm}$, when the temperature was $25^{\circ} \mathrm{C}$, while the particle size shrank to $114 \mathrm{~nm}$ at $40{ }^{\circ} \mathrm{C}$. That was similar to PPhe80, but PPhe120 copolymer was more hydrophobic, and the distribution of particle size became narrower above LCST. For the copolymer of PPhe40, (Fig. 6a) with the increase of temperature, the hydrogen was destroyed gradually, and the particle size was compressed from 72.2 to $39 \mathrm{~nm}$ because of the hydrophobic interaction of benzene rings and amide bonds. Meanwhile, there had little change in the particle size distribution width before and after heating, probably due to the weakly hydrophobic interaction of PPhe40. The particle size of PPhe40 could shift with temperature variation, which showed that PPhe40 copolymer also had certain sensitivity to temperature, but the sensitivity was much weaker than that of PPhe80 and PPhe120. Figure 6(d-i) showed the TEM images of PPhen copolymers obtained by the self-assembly in aqueous solution with increasing temperature at different $\mathrm{pHs}$ values. There were consistent results with DLS assay, the particle sizes of aggregates at 

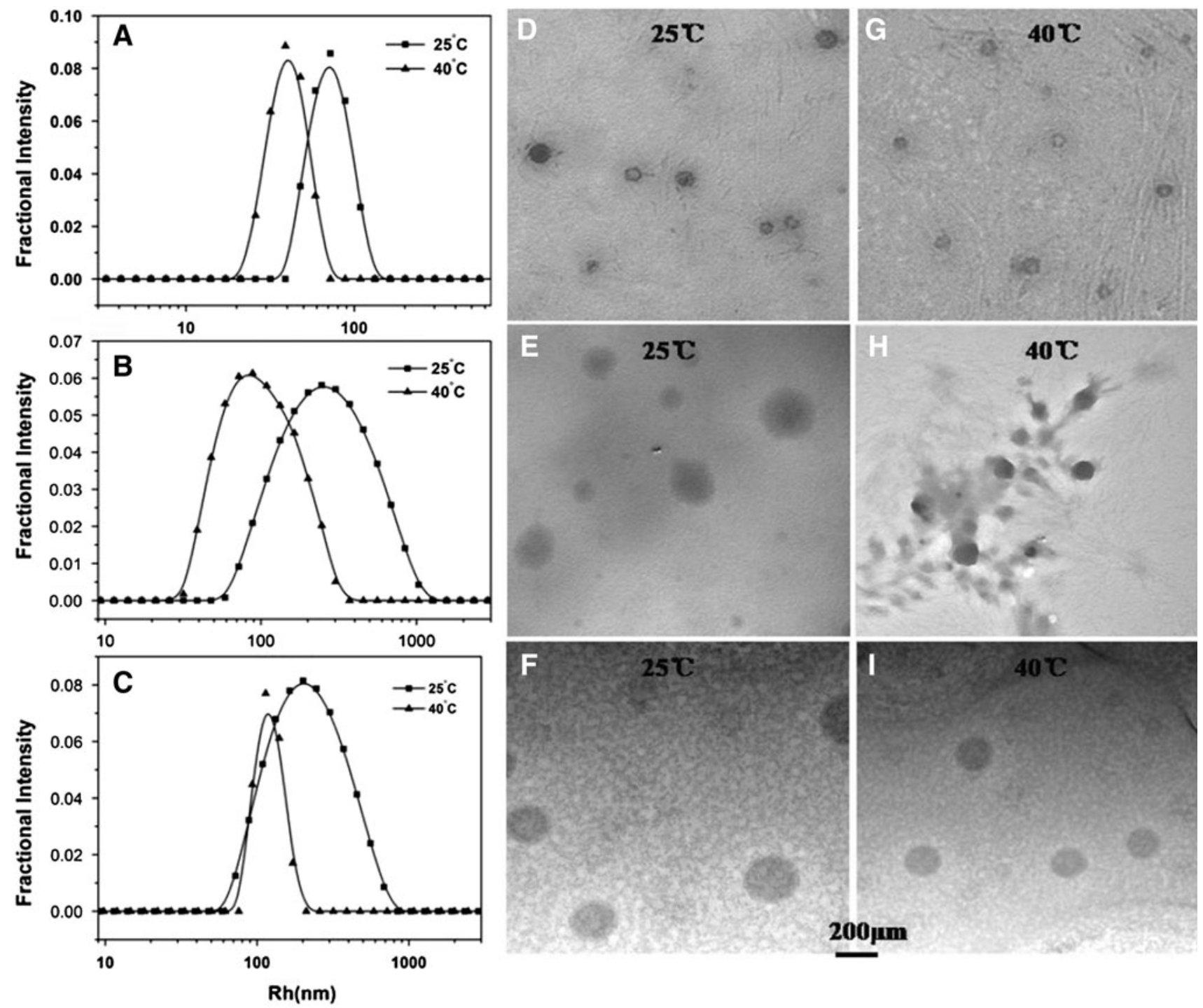

Fig. 6 The representative size distribution curves of PPhe40 (a), PPhe 80 (b), and PPhe120 (c) at $0.5 \mathrm{mg} / \mathrm{mL}$ at pH9.8, pH9.8, and pH8.0, respectively. The rectangular and triangular symbols denote the data collected at 25 and $40{ }^{\circ} \mathrm{C}$. TEM images of PPhe40 ( $\mathbf{d}$ and $\mathbf{g}$ ),

PPhe80 (e and h), and PPhe120 (f and i) at pH9.8, pH9.8, and pH8.0, respectively, with a concentration of $0.1 \mathrm{mg} / \mathrm{mL}$ at different temperatures

$25^{\circ} \mathrm{C}$ were larger than those at $40{ }^{\circ} \mathrm{C}$, which could also indicate that the PPhen copolymers had thermo-responsive properties.

\section{Conclusion}

In this study, thermo- and $\mathrm{pH}$ dual responsive PPhen copolymers were successfully synthesized by hydrophobic phenylalanine grafting of HPEI. The improved cytocompatibility of PPhen copolymers was due to the introduction of biocompatible Phe moieties, which shielded the high positive charge density on the surface of PEI. The obtained

copolymers showed LCST in aqueous solution. LCSTs of these copolymers could be altered from 7.2 to $59.6^{\circ} \mathrm{C}$ by varying the degree of amidation by phenylalanine groups and $\mathrm{pH}$ of solution. The obtained thermo- and $\mathrm{pH}$ dual responsive copolymers might be more suitable for being used as 'smart' polymers in biomedical and biotechnological fields.

Acknowledgments The authors are thankful to the National Natural Science Foundation of China (Grant Nos. 51203132, 51222307, 51303173 and 51021003), the Ministry of Science and Technology of China (International cooperation and communication program 2011DFR51090), Jilin province science and technology development program $(20130521011 \mathrm{JH})$ for financial support to this work. 
Open Access This article is distributed under the terms of the Creative Commons Attribution License which permits any use, distribution, and reproduction in any medium, provided the original author(s) and the source are credited.

\section{References}

Alarcon, C.D.H., S. Pennadam, and C. Alexander. 2005. Stimuli responsive polymers for biomedical applications. Chemical Society Reviews 34: 276-285.

Amin, M.C.I.M., N. Ahmad, N. Halib, and I. Ahmad. 2012. Synthesis and characterization of thermo- and $\mathrm{pH}$-responsive bacterial cellulose/acrylic acid hydrogels for drug delivery. Carbohydrate Polymers 88: 465-473.

Boussif, O., F. Lezoualch, M.A. Zanta, M.D. Mergny, D. Scherman, B. Demeneix, and J.P. Behr. 1995. A Versatile vector for gene and oligonucleotide transfer into cells in culture and in-vivopolyethylenimine. Proceedings of the National Academy of Sciences of the United States of America 92: 7297-7301.

Casolaro, M., E. Paccagnini, R. Mendichi, and Y. Ito. 2005. Stimuliresponsive polymers based on L-phenylalanine residues: protonation thermodynamics of free polymers and cross-linked hydrogels. Macromolecules 38: 2460-2468.

Cha, R.T., Z.B. He, and Y.H. Ni. 2012. Preparation and characterization of thermal/pH-sensitive hydrogel from carboxylated nanocrystalline cellulose. Carbohydrate Polymers 88: 713-718.

Chaterji, S., I.K. Kwon, and K. Park. 2007. Smart polymeric gels: redefining the limits of biomedical devices. Progress in Polymer Science 32: 1083-1122.

Chen, F.J., J.B. Guo, O.Y. Jin, and J. Wei. 2013a. A temperature and $\mathrm{pH}$ double sensitive cholesteric polymer film from a photopolymerizable chiral hydrogen-bonded assembly. Chinese Journal of Polymer Science 31: 630-640.

Chen, J., H.Y. Tian, X. Dong, Z.P. Guo, Z.X. Jiao, F.F. Li, A. Kano, A. Maruyama, and X.S. Chen. 2013b. Effective tumor treatment by VEGF siRNA complexed with hydrophobic poly(amino acid)-modified polyethylenimine. Macromolecular Bioscience 13: $1438-1446$.

Chen, J., H.Y. Tian, Z.P. Guo, J.L. Xia, A. Kano, A. Maruyama, X.B. Jing, and X.S. Chen. 2009. A highly efficient siRNA carrier of PBLG modified hyperbranched PEI. Macromolecular Bioscience 9: 1247-1253.

Costa, R.R., C.A. Custodio, A.M. Testero, F.J. Arias, J.C. RodriguezCabello, N.M. Alves, and J.F. Mano. 2009. Stimuli-responsive thin coatings using elastin-like polymers for biomedical applications. Advanced Functional Materials 19: 3210-3218.

Dobrynin, A.V., and M. Rubinstein. 2005. Theory of polyelectrolytes in solutions and at surfaces. Progress in Polymer Science 30: $1049-1118$.

Haba, Y., A. Harada, T. Takagishi, and K. Kono. 2004. Rendering poly(amidoamine) or poly(propylenimine) dendrimers temperature sensitive. Journal of the American Chemical Society 126: 12760-12761.

Haba, Y., C. Kojima, A. Harada, and K. Kono. 2006. Control of temperature-sensitive properties of poly(amidoamine) dendrimers using peripheral modification with various alkylamide groups. Macromolecules 39: 7451-7453.

Khaydarov, R.A., R.R. Khaydarov, and O. Gapurova. 2010. Water purification from metal ions using carbon nanoparticle-conjugated polymer nanocomposites. Water Research 44: 1927-1933.

Kim, I.S., and I.J. Oh. 2005. Drug release from the enzymedegradable and $\mathrm{pH}$-sensitive hydrogel composed of glycidyl methacrylate dextran and poly(acrylic acid). Archives of Pharmacal Research 28: 983-987.
Kim, W.J., and S.W. Kim. 2009. Efficient siRNA delivery with nonviral polymeric vehicles. Pharmaceutical Research 26: 657-666.

Kojima, C., K. Yoshimura, A. Harada, Y. Sakanishi, and K. Kono. 2009. Synthesis and characterization of hyperbranched poly(glycidol) modified with $\mathrm{pH}$ - and temperature-sensitive groups. Bioconjugate Chemistry 20: 1054-1057.

Lei, Y.G., S.X. Huang, P. Sharif-Kashani, Y. Chen, P. Kavehpour, and T. Segura. 2010. Incorporation of active DNA/cationic polymer polyplexes into hydrogel scaffolds. Biomaterials 31: 9106-9116.

Liu, G.Q., X.L. Li, S.D. Xiong, and Z.S. Xu. 2012. Preparation and research on micellization behavior of thermo-sensitive fluorinecontaining amphiphilic graft copolymer. Chemical Journal of Chinese Universities 33: 624-629.

Liu, H.J., Y. Chen, and Z. Shen. 2007. Thermoresponsive hyperbranched polyethylenimines with isobutyramide functional groups. Journal of Polymer Science Part A 45: 1177-1184.

Oda, Y., S. Kanaoka, and S. Aoshima. 2010. Synthesis of dual pH/ temperature-responsive polymers with amino groups by living cationic polymerization. Journal of Polymer Science Part A 48: 1207-1213.

Pang, Y., Q. Zhu, D.L. Zhou, J.Y. Liu, Y. Chen, Y. Su, D.Y. Yan, X.Y. Zhu, and B.S. Zhu. 2011. Synthesis of backbone thermo and $\mathrm{pH}$ dual-responsve hyperbranched poly(amine-ether)s through proton-transfer polymerization. Journal of Polymer Science Part A 49: 966-975.

Park, Y.M., B.A. Shin, and I.J. Oh. 2008. Poly(L-lactic acid)/ polyethylenimine nanoparticles as plasmid DNA carriers. Archives of Pharmacal Research 31: 96-102.

Sakaguchi, N., C. Kojima, A. Harada, and K. Kono. 2008. Preparation of $\mathrm{pH}$-sensitive poly(glycidol) derivatives with varying hydrophobicities: their ability to sensitize stable liposomes to $\mathrm{pH}$. Bioconjugate Chemistry 19: 1040-1048.

Schmaljohann, D. 2006. Thermo- and pH-responsive polymers in drug delivery. Advanced Drug Delivery Reviews 58: 1655-1670.

Strozyk, M.S., M. Chanana, I. Pastoriza-Santos, J. Perez-Juste, and L.M. Liz-Marzan. 2012. Protein/polymer-based dual-responsive gold nanoparticles with $\mathrm{pH}$-dependent thermal sensitivity. Advanced Functional Materials 22: 1436-1444.

Tian, H.Y., J. Chen, and X.S. Chen. 2013. Nanoparticles for gene delivery. Small 9: 2034-2044.

Tian, H.Y., Z.H. Tang, X.L. Zhuang, X.S. Chen, and X.B. Jing. 2012. Biodegradable synthetic polymers: preparation, functionalization and biomedical application. Progress in Polymer Science 37: 237-280

Tian, H.Y., W. Xiong, J.Z. Wei, Y. Wang, X.S. Chen, X.B. Jing, and Q.Y. Zhu. 2007. Gene transfection of hyperbranched PEI grafted by hydrophobic amino acid segment PBLG. Biomaterials 28: 2899-2907.

Tono, Y., C. Kojima, Y. Haba, T. Takahashi, A. Harada, S. Yagi, and K. Kono. 2006. Thermosensitive properties of poly(amidoamine) dendrimers with peripheral phenylalanine residues. Langmuir 22: 4920-4922.

Vicennati, P., A. Giuliano, G. Ortaggi, and A. Masotti. 2008. Polyethylenimine in medicinal chemistry. Current Medicinal Chemistry 15: 2826-2839.

Won, Y.W., S.M. Yoon, K.M. Lee, and Y.H. Kim. 2011. Poly(oligo-Darginine) with internal disulfide linkages as a cytoplasm-sensitive carrier for siRNA delivery. Molecular Therapy 19: 372-380.

Yu, S.F., Z. Wang, G.L. Wu, Y.N. Wang, H. Gao, and J.B. Ma. 2012. Anti-tumor drug Delivery of a $\mathrm{pH}$-sensitive poly(aspartic acid)containing block copolymer. Acta Polymerica Sinica 4: 427-432.

Zhang, Z., L. Chen, C.W. Zhao, Y.Y. Bai, M.X. Deng, H.L. Shan, X.L. Zhuang, X.S. Chen, and X.B. Jing. 2011. Thermo- and pHresponsive HPC-g-AA/AA hydrogels for controlled drug delivery applications. Polymer 52: 676-682. 